\title{
Análise de situações pedagógicas de Estatística num livro didático
}

\author{
Keli Cristina Conti
}

\section{Resumo}

Este artigo busca descrever dois dos encontros de um grupo de estudos formado por professores e futuros professores da Educação Infantil e dos anos iniciais do Ensino Fundamental que, com o tempo, constituiu um contexto colaborativo. Nos encontros descritos, a ênfase foi para a análise de situações pedagógicas que envolviam a Estatística em livros didáticos de $1^{\circ}$ e $2^{\circ}$ ano do Ensino Fundamental. Com isso também objetivamos sistematizar e ampliar algumas reflexões decorrentes de uma pesquisa de doutorado, de abordagem qualitativa. Consideramos que a participação em um grupo de estudos contribuiu para que os integrantes passassem a dirigir outros olhares para a prática de sala de aula e para os materiais utilizados para o ensino e aprendizagem da Estatística.

Palavras-chave: Educação Matemática; Educação Estatística; Contexto colaborativo.

\section{Analysis of pedagogical situations of Statistics in a didactic book}

\section{Abstract}

This article aims to describe two of the meetings of a group of studies, formed by teachers and future teachers of Early Childhood Education and the initial years of Elementary Education, which, over time, constituted a collaborative context. In the meetings described, the emphasis was on the analysis of pedagogical situations that involved Statistic in textbooks of 1 st and 2 nd year of Elementary School. With this we also aim to systematize and amplify some reflections resulting from a doctoral research, with

Doutora em Educação na área de concentração "Ensino e Práticas Culturais" pela Universidade Estadual de Campinas (Unicamp). Professora Adjunta da Faculdade de Educação da Universidade Federal de Minas Gerais (FaE/ UFMG). 
a qualitative approach. Participation in a study group was considered to have contributed to the participation of other members in the classroom and to the materials used for the teaching and learning of Statistics.

Keywords: Mathematics Education; Statistical Education; Collaborative Context.

\section{Análisis de situaciones pedagógicas de Estadísti- ca en un libro didáctico}

\section{Resumen}

Este artículo busca describir dos de los encuentros de un grupo de estudios, formado por profesores y futuros profesores de Educación Infantil y de los años iniciales de la Enseñanza Fundamental que, con el tiempo, constituyó un contexto colaborativo. En los encuentros descritos, el énfasis fue para el análisis de situaciones pedagógicas que envolvían la Estadística en libros didácticos de $1^{\circ}$ y $2^{\circ}$ año de la Enseñanza Fundamental. Con ello también objetivamos sistematizar y ampliar algunas reflexiones derivadas de una investigación de doctorado, de abordaje cualitativo. Consideramos que la participación en un grupo de estudios contribuyó a que los integrantes pasasen a dirigir otras miradas para la práctica del aula y para los materiales utilizados para la enseñanza y el aprendizaje de la estadística. Palabras clave: Educación Matemática; Educación Estadística; Contexto colaborativo.

\section{Introdução}

Este artigo é baseado em uma pesquisa de doutorado cujo objetivo principal foi compreender as aprendizagens e o desenvolvimento profissional de professores e futuros professores da Educação Infantil e dos anos iniciais do Ensino Fundamental (estudantes de 6 a 10 anos) na perspectiva do letramento estatístico em contextos colaborativos.

Embora a investigação tenha como pilares principais os estudos sobre Educação Estatística, letramento estatístico, desenvolvimento profissional e contexto colaborativo, escolhi, neste artigo, revisitar alguns momentos vídeo-gravados, durante dois encontros do grupo, que davam destaque às discussões de situações pedagógicas que envolviam Estatística, presentes em livros didáticos, destacando as bases de conhecimento de Shulman (1987). 
A seguir, buscamos contextualizar brevemente a pesquisa, descrever o grupo de estudos criado e analisado durante o trabalho de campo da pesquisa e que se constituiu como um contexto colaborativo, dando destaque para situações pedagógicas de Estatística presentes num livro didático de $1^{\circ}$ e $2^{\circ}$ ano do Ensino Fundamental.

\section{Contextualizando brevemente a pesquisa}

No contexto amplo da pesquisa ${ }^{1}$, objetivamos, do ponto de vista investigativo, compreender o processo de desenvolvimento profissional na perspectiva do letramento estatístico em contextos colaborativos, evidenciando indícios de desenvolvimento de conhecimento e de desenvolvimento pessoal como participantes de um grupo de professores e futuros professores que se reúnem para estudar Estatística.

O contexto mais amplo da pesquisa foi caracterizado, metodologicamente, como uma investigação qualitativa, buscando valorizar a descrição detalhada das pessoas, das interações, de suas concepções e da trajetória vivenciada pelo grupo.

De acordo com Bogdan e Biklen (1994), a investigação qualitativa possui cinco características:

1. Na investigação qualitativa a fonte direta de dados é o ambiente natural, constituindo o investigador o instrumento principal;

2. A investigação qualitativa é descritiva;

3. Os investigadores qualitativos interessam-se mais pelo processo do que simplesmente pelos resultados ou produtos;

4. Os investigadores qualitativos tendem a analisar os seus dados de forma indutiva;

5. O significado é de importância vital na abordagem qualitativa (BOGDAN; BIKLEN, 1994, p. 47-50).

Aqui são revisitados e descritos dois encontros de um grupo colaborativo. $\mathrm{O}$ contexto da pesquisa envolve 20 encontros. Todos os encontros descritos e analisados podem ser encontrados em Conti (2015). 
Consideramos que essas características são adequadas para o estudo realizado ${ }^{2}$, pois, cientes da importância do contexto e sua influência no comportamento dos participantes, recolhemos os dados no grupo de estudos, ou seja, na situação, complementando as informações quando necessário e, com isso, buscando captar a riqueza nos dados, na dinâmica, nos detalhes, respeitando os participantes, descrevendo e transcrevendo os encontros e usando o diário de pesquisa. Também buscamos mostrar como nossas expectativas se traduziram nos encontros do grupo, durante as discussões de situações pedagógicas, no estudo e na interação entre os participantes. Além disso, os dados não foram analisados para confirmar ou refutar uma hipótese prévia, mas para mostrar a forma com que foram agrupados durante o percurso, ou seja, foram utilizados de forma indutiva, interessando-nos mais pelo percurso dos professores no grupo e pela forma com que dão sentido ao seu desenvolvimento profissional do que por um produto final.

No que se refere à recolha de dados da pesquisa, foram utilizadas ${ }^{3}$ gravações de áudio e vídeo ${ }^{4}$, ficha de identificação do perfil dos participantes preenchida individualmente, uma caracterização oral respondida em grupo, material trazido e produzido pelos participantes e análises narrativas produzidas por participantes do grupo. Além disso, também tivemos o diário de pesquisa, que subsidiou a análise e a escrita da tese. Passamos agora à descrição do grupo de estudos.

\section{grupo de estudos}

Almejamos, desde o planejamento da pesquisa de campo do trabalho, uma perspectiva em que "professores da escola e da universidade, mestrandos e doutorandos e futuros docentes podiam, juntos, aprender a enfrentar o desafio da escola atual" (FIORENTI-

2 Bogdan e Biklen (1994) apontam que nem todos os estudos deixam todas as características registradas fortemente e ainda podem apresentar uma ou mais características.

3 Nem todos esses materiais aparecem ou tem destaque neste artigo.

$4 \quad$ Pela própria pesquisadora. 
NI, 2011, p. 7, grifo do autor). Quando assumimos a ideia de "juntos", estamos pensando na proposta de trabalho em grupo, de um grupo colaborativo, assumindo, como diz Fiorentini (2004), que, na colaboração,:

[...] todos trabalham conjuntamente (co-laboram) e se apóiam mutuamente, visando atingir objetivos comuns negociados pelo coletivo do grupo. $\mathrm{Na}$ colaboração, as relações, portanto, tendem a ser não-hierárquicas, havendo liderança compartilhada e co-responsabilidade pela condução das ações (FIORENTINI, 2004, p. 52).

De acordo com Coelho (2010, p. 17), quando um grupo é formado nesse sentido da colaboração, com pessoas dispostas a compartilhar espontaneamente algo de interesse comum - no nosso caso, o letramento estatístico -, "as distintas contribuições e os diferentes níveis de participação oferecem condições satisfatórias para a geração de conhecimento e para o crescimento pessoal dos participantes".

Sobre isso, Fiorentini (2010, p. 582) defende que

Em cada grupo colaborativo os formadores, professores e futuros professores analisam e discutem os problemas e desafios trazidos pelos professores, episódios de aula narrados e documentados pelos professores, e negociam conjuntamente significados e outras possibilidades de intervenção em suas práticas escolares, sobretudo tarefas e atividades exploratório -investigativas (FIORENTINI, 2010, p. 582).

Por concordarmos com as ideias dos autores citados, pedimos autorização a uma instituição de ensino superior de cunho privado, na qual atuava como professora, para a utilização de um espaço ali disponível, chamado de "Oficina Pedagógica", para a realização de encontros do grupo de estudos. Com a concordância da direção em relação à utilização do espaço, enviamos um convite, por e-mail, a professores e futuros professores, que eram meus alunos no momento, a ex-alunos e colegas professores que atuam na rede pública e particular na cidade de Atibaia/SP. Com isso, demos 
início ao movimento de criação do grupo, utilizando o espaço cedido na referida instituição.

Felizmente, em setembro de 2010, havia vários interessados em conhecer as propostas de trabalho e estudo. A partir de então, o grupo se reuniu regularmente e voluntariamente até dezembro de 2011, totalizando 20 encontros.

O grupo chegou a ter 20 interessados, mas, na maior parte do tempo, foi formado por 9 participantes: Keli, pesquisadora e formadora de professores, que atuava nos cursos de Pedagogia e Matemática; Silvana, professora aposentada, com experiência de atuação na Educação Infantil (crianças de 3 a 6 anos); Eduardo, professor em início de carreira, atuando nos anos iniciais do Ensino Fundamental (crianças de 6 a 10 anos); Rosana, estudante de Pedagogia, que já atuava como professora na Educação Infantil; cinco estudantes de Pedagogia, sendo que Roseli e Mie já realizavam atividade de estágio nos anos iniciais do Ensino Fundamental, por estarem no último ano da primeira graduação, e Thaynara, Érica e Cíntia encontravam-se no período inicial de estágio nos anos iniciais do Ensino Fundamental, por estarem no $2^{\circ}$ ano da primeira graduação. Portanto, eles já tinham nível superior (Curso de Pedagogia), Keli, Silvana e Eduardo; ou estavam cursando, caso de Rosana, Roseli, Mie, Thaynara, Érica e Cíntia. Todos os participantes concordaram que fosse usado seu primeiro nome $e^{5}$ na divulgação da pesquisa.

A seguir, serão apresentados os temas estatísticos de estudos, buscando contemplar as bases de conhecimentos elencados por Shulman (1987) em sintonia com as demandas dos participantes.

\section{Temas estatísticos de estudo}

Nos encontros, com duração aproximada de 50 minutos a 1 hora, procuramos nos inspirar na dinâmica de trabalho e pesquisa de grupos colaborativos proposta por Fiorentini et al. (2011, p. 215): os formadores atuam em função das demandas dos professores e futuros professores, que trazem problemas e desafios das práticas

5 Conforme termo de autorização assinado pelos participantes. 
escolares, para, juntos, estudar, problematizar, refletir, investigar e escrever sobre a complexidade de ensinar e aprender nas escolas.

Para a seleção dos temas que estudaríamos inicialmente nos encontros, foram levadas por mim às reuniões várias publicações e materiais que contemplassem os conhecimentos elencados por Shulman (1987), buscando atuar em função das demandas, como apontado por Fiorentini (2011).

Shulman (1987, p. 8) afirma que, para agir na sala de aula, o professor deve ter uma base de conhecimento para o ensino e dominar o processo pelo qual os conhecimentos profissionais são construídos. O referido autor explicitou alguns tipos de conhecimento ou categorias que chamou de base de conhecimento, considerando o conceito de ensino como profissão: "conhecimento de conteúdo específico"; "conhecimento pedagógico geral"; "conhecimento do currículo"; "conhecimento pedagógico do conteúdo"; "conhecimento dos estudantes e suas características"; "conhecimento dos contextos educativos"; e "conhecimento dos objetivos, metas e valores educacionais".

Tomando como referência Shulman (1987) e Mizukami (2004), detalhamos esses conhecimentos, exemplificando-os à luz de nossos referenciais do ensino de Estatística:

1. Conhecimento de conteúdo específico: conhecimento dos conteúdos das disciplinas escolares, ou conhecimento da matéria/assunto. Considerado imprescindível para a docência e para que o professor possa constituir-se como mediador entre os conhecimentos historicamente produzidos e os conhecimentos escolares de uma determinada modalidade de ensino, como os anos iniciais do Ensino Fundamental, por exemplo, oferecendo condições para que o estudante se aproprie deles. No caso do ensino de Estatística, o conhecimento de conteúdo específico para o ensino trata, por exemplo, de identificar os conteúdos estatísticos para a interpretação de determinada reportagem que apresenta um gráfico. 
2. Conhecimento pedagógico geral: considerado um conhecimento que transcende a área específica, ou seja, são os conhecimentos necessários à transformação do conteúdo a ser ensinado em conteúdo a ser aprendido, incluindo, para isso, processos didáticos, motivação, estratégias de manejo da sala de aula, organização, entre outros. É constituído pelo conhecimento da Estatística e de sua transformação em conteúdo a ser aprendido, transcendendo a área específica (Estatística).

3. Conhecimento do currículo: refere-se ao conhecimento tanto do currículo específico da matéria/assunto ou disciplina de determinada modalidade de ensino quanto da relação delas com a organização e a estruturação dos conhecimentos escolares. Ajuda os professores a compreenderem como os conteúdos a serem ensinados se interligam ao longo do tempo. Por exemplo, como a descrição de uma população (estudantes da turma) pode auxiliar, no futuro, na compreensão do uso de amostras para fazer inferências sobre uma população bem maior.

4. Conhecimento pedagógico do conteúdo: é considerado específico da docência e é construído pelos professores a partir de suas atuações em situações concretas de ensino e aprendizagem. O conhecimento pedagógico da Estatística implica, especificamente, o conhecimento necessário para as tarefas relacionadas ao ensino, como a gestão da sala de aula, que vão além do escopo do assunto, e é constituído constantemente pelo professor ao ensinar a matéria (Estatística). Segundo Mizukami (2004), é enriquecido com a interação dos diferentes tipos de conhecimentos e é o único conhecimento em que o professor pode estabelecer uma relação de protagonismo. Possuir o conhecimento da Estatística e de seu ensino implica ter um repertório de estratégias de conteúdos específicos para os conceitos a serem ensinados. Esse 
conhecimento da Estatística e de seu ensino emerge da prática dos professores experientes ou inexperientes.

5. Conhecimento dos estudantes e suas características: envolve o conhecimento dos estudantes e da forma como aprendem, de acordo com suas especificidades, nas dimensões cognitiva, emocional, social, motora e interacional. Consiste no entrelaçamento do conhecimento da Estatística com o conhecimento do modo como os estudantes pensam, sabem e aprendem esse conteúdo, antecipando, inclusive, possíveis dificuldades.

6. Conhecimento dos contextos educativos: envolve tanto o microssistema relacionado ao trabalho dos estudantes (em grupos ou na sala de aula) quanto o microssistema que abrange as particularidades sociais e culturais da comunidade em que está a escola, passando pela administração e gestão da escola. Ajudaria a entender questões subjacentes, como, por exemplo, o currículo como política, em relação ao conhecimento oficial, e sua relação com os materiais disponíveis ou com as propostas de formação de professores.

7. Conhecimento dos objetivos, das metas e dos valores educacionais: engloba o conhecimento dos fins e propósitos educacionais e de seus fundamentos filosóficos e históricos, e também contribui para a compreensão de questões relativas a propostas pedagógicas e de formação, por exemplo.

Embora as bases do conhecimento estejam apresentadas separadamente, na prática, estão todas entrelaçadas, daí a razão de denominá-las "complexas" e nossa intenção não é dividi-las, pois proceder dessa forma seria banalizá-las e reduzir sua complexidade. Porém consideramos que essas bases de conhecimento nos ajudam a compreender as experiências que compartilhamos com os participantes do grupo de estudos no contexto colaborativo e nas análises do processo ocorrido. Em especial, essas bases de conhecimento nos 
ajudam nas análises das situações pedagógicas do livro didático que entrelaçava, no processo de construção de conhecimento, todas as bases de conhecimento que foram propostas por Shulman (1987) e por Cochran-Smith e Lytle (1999, p. 13), ou seja, o entendimento de que estamos partindo do pressuposto de que "o conhecimento é construído socialmente por professores que trabalham juntos" e também "por professores e estudantes, à medida que trocam suas experiências prévias, seu conhecimento anterior, seus recursos culturais e linguísticos e os recursos textuais e materiais de sala de aula".

\section{Surgimento da temática a partir dos participantes}

No período de planejamento dos encontros, no que diz respeito à sugestão de temáticas e de metodologia para o segundo semestre de 2011, quando o grupo já se reunia por quase um ano, as avaliações dos encontros, realizadas junto aos participantes do grupo, reforçaram o desejo de trabalhar, estudar, discutir a sala de aula e as situações pedagógicas para serem ali desenvolvidas, ligadas ao currículo. Ou seja, ficou clara a importância, para os membros do grupo, de desenvolver o conhecimento do currículo (SHULMAN, 1987), próximo à cultura escolar - conhecimento dos contextos educativos, também de acordo com Shulman (1987) - , pois consideraram ser este um desafio do professor: conduzir uma proposta ligada às temáticas que estudávamos, embasadas por aportes teóricos, de forma a realmente construir conhecimento. A seguir, descrevemos os encontros do grupo de estudos a partir das escolhas dos próprios participantes.

\section{Situações pedagógicas de Estatística num livro di- dático}

As descrições a seguir são fruto de dois encontros do grupo de estudos, realizados em 21/10/2011 e 04/11/2011, planejados para atender ao pedido dos participantes e adaptados para apresentação neste artigo. Selecionamos previamente situações pedagógicas envolvendo gráficos e tabelas, presentes em livros didáticos dos anos iniciais do Ensino Fundamental, adotados pela rede municipal de Atibaia. Foram discutidas três situações pedagógicas destinadas ao $1^{\circ}$ ano do Ensino Fundamental e três destinadas ao $2^{\circ}$ ano do Ensino Fundamental. 
A primeira delas, segundo as orientações dos autores (MILANI; IMENES; LELLIS, 2008a, p. 42), tinha como objetivos:

- Construir a noção de gráfico;

- Exercitar a contagem de 1 a 10 e seguintes;

- Propiciar contato com a escrita numérica de dez, onze e doze;

- Trabalhar com a correspondência um a um;

- Comparar números por meio da relação entre quantidades e sua representação geométrica.

Os autores apresentavam uma situação desenvolvida numa classe imaginária, em que crianças haviam votado nas opções "bolaqueimada, pega-pega, pula-macaco e estátua” (MILANI; IMENES; LELLIS, 2008a, p. 42), e propunham algumas questões a respeito do gráfico. A partir disso, as crianças seriam motivadas a construir o gráfico que mostrasse a preferência de sua classe (Figura 1).

Figura 1: Matrizpara a construção de um gráfico com a turma

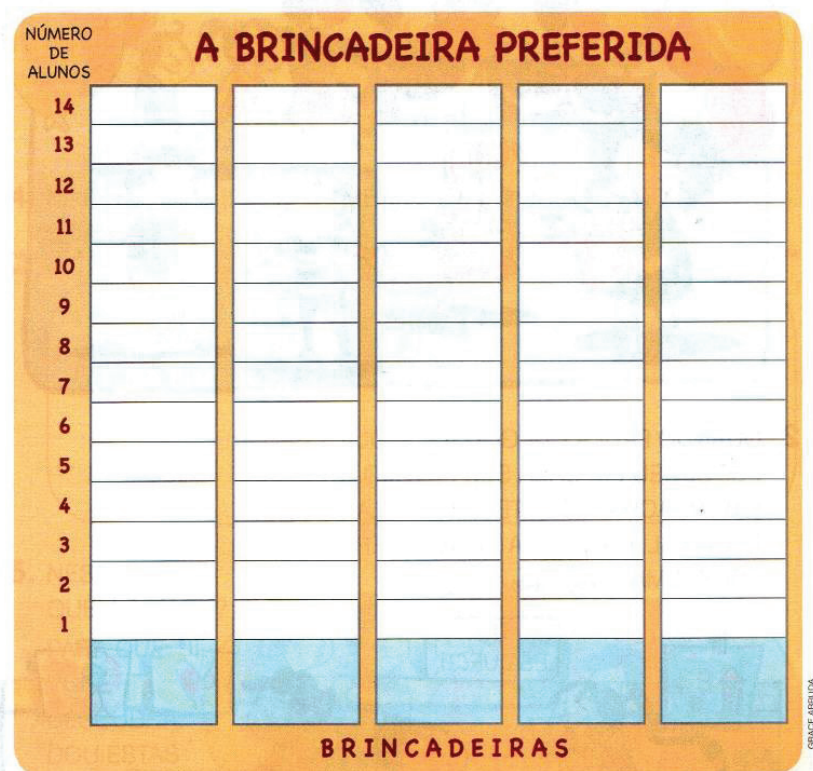

Fonte: Milani, Imenes e Lellis (2008a, p. 43) 
Embora tivéssemos lido os objetivos apresentados pelos autores, questionamos o proposto na situação:

\section{Roseli: Por que vamos selecionar a brincadeira preferida? \\ Mie: Para quê?}

Keli: Senão fica uma coisa assim: constatamos que a brincadeira preferida da turma é pega-pega [fazendo referência ao gráfico apresentado pelos autores de livro didático]. Muito bem, vamos passar para a próxima atividade!

Mie: Qual o motivo da escolha, para que en vou escolher?

Keli: Eu acho importante escolher e implicar em alguma coisa, senão fica uma atividade para cumprir o conteúdo, uma estatística pela Estatística (Arquivo de vídeo da pesquisadora. Intervalo de tempo 0:06:36 a 0:07:18).

Concluímos que, para nós, o que faltaria no desenvolvimento da situação seria a implicação de algo, como por exemplo, diante da pergunta "Qual sua brincadeira preferida?", que seria feita a escolha e isso implicaria o desenvolvimento dessa brincadeira na escola, entre as crianças. Outra indicação foi a inclusão da questão "Quantos estudantes participaram da pesquisa?". Watson (2006) também reforça que, quando os estudantes produzem suas próprias representações com base num conjunto de dados, ocorre outro grau de envolvimento, criatividade e conexões, além de possibilitar um contexto motivador e de interesse dos estudantes.

A segunda proposta discutida abordava o mês de aniversário das crianças, o que nos fez lembrar da situação pedagógica já discutida no grupo, mas o registro dessa situação se dava com um gráfico de barras. Seus objetivos, de acordo com Milani, Imenes e Lellis (2008a, p. 120), eram: "Fazer enquetes e organizar dados; Construir gráfico de barras". Em sua comanda, a proposta trazia:

A professora pergunta:

- Quem faz aniversário em Janeiro?

Aí, os aniversariantes de Janeiro levantam a mão.

Você pinta um quadradinho para cada um deles na linha correspondente a Janeiro. Depois ela faz a mesma pergunta para os outros meses e você repete o procedimento.

Ao final terá construído um gráfico (MILANI; IMENES; LELLIS, 2008a, p. 120). 
Roseli, assim, apresentou suas impressões, baseada no que tinha visto no seu estágio:

Roseli: Esse gráfico fica confuso para os alunos! [apontando para a ilustração do livro didático]. Fica melhor esse do Eduardo [participante do grupo]. Sabe por quê? Eu substituí uma professora, no primeiro ano e vi no material de atividades esse gráfico e lembrei na hora e vi que não deu muito certo. Havia vários lugares apagados (Arquivo de vídeo da pesquisadora. Intervalo de tempo 0:24:45 a 0:25:22).

Concluímos que talvez fosse melhor a criança ter experiências com o gráfico de colunas antes do gráfico de barras (Figura 2), pois isso poderia melhorar seu entendimento. Nesse sentido, mais uma vez, Watson (2006) aponta para o protagonismo do estudante, para sua liberdade na escolha da forma como deseja representar os dados, além da criatividade, mesmo que isso não satisfaça ainda as convenções estatísticas.

Figura 2: Gráfico de barras

MESES
\begin{tabular}{|l|l|l|l|l|l|l|l|l|}
\hline 1. JANEIRO & & & & & & & & \\
\hline 2. FEVEREIRO & & & & & & & & \\
\hline 3. MARÇO & & & & & & & & \\
\hline 4. ABRIL & & & & & & & & \\
\hline 5. MAIO & & & & & & & & \\
\hline 6. JUNHO & & & & & & & & \\
\hline 7. JULHO & & & & & & & & \\
\hline 8. AGOSTO & & & & & & & & \\
\hline 9. SETEMBRO & & & & & & & & \\
\hline 10. OUTUBRO & & & & & & & & \\
\hline \hline 11. NOVEMBRO & & & & & & & & \\
\hline \hline 12. DEZEMBRO & & & & & & & & \\
\hline
\end{tabular}

Fonte: Milani, Imenes e Lellis (2008a, p. 120) 
Já a terceira atividade selecionada, ainda para o $1^{\circ}$ ano, apresentava um gráfico montado, representando os pontos de um torneiro de boliche. Mie quis saber por que o eixo horizontal do gráfico, que apresentava os pontos obtidos no boliche, ia de "dois em dois". Investigando a situação pedagógica no contexto do livro didático (MILANI; IMENES; LELLIS, 2008a), notamos que, nas páginas anteriores, era apresentado um jogo de boliche e havia imagens e comandas que faziam menção a um torneio em que cada pino valia dois pontos. Nas orientações, havia indicação dos autores para que o jogo realizado pelas crianças fosse construído com garrafas PET. Nossas discussões nos levaram a concluir que as situações pedagógicas apresentadas no livro para serem realizadas pelas crianças não implicavam a realização do jogo, ficavam mais como uma sugestão ao professor. Sabemos do potencial do uso dos jogos no desenvolvimento dos estudantes, mas, infelizmente, ainda há preconceito na realização desse tipo de situação, tida como algo sem importância ou também que vá tomar muito tempo da rotina escolar, gerar agitação e mais trabalho para o professor.

$\mathrm{Na}$ sequência proposta pelo livro didático, quando chegava a hora da análise do gráfico, os autores o apresentavam pronto, acompanhado de perguntas do tipo "Quantos alunos fizeram 16 pontos?", que se repetia com outras quantidades, ou "Quem fez mais pontos nesse torneio?” (MILANI; IMENES; LELLIS, 2008a, p. 149).

Considerando nossa interlocução com os textos estudados, caso a situação pedagógica seja desenvolvida exatamente da forma como é apresentada no livro didático, mais uma vez as crianças não decidem sobre o que querem pesquisar e não são protagonistas, não produzem dados, não os classificam e nem escolhem a forma como poderão apresentá-los. Para nós, o ideal seria que as crianças construíssem seu jogo de boliche, jogassem, assistissem às jogadas de seus colegas, escolhessem como poderiam registrar seus pontos e como poderiam organizá-los, de forma a responder questões levantadas por eles próprios a respeito desses dados. Ou seja, concordamos com Watson (2006) sobre o papel fundamental da criação 
e da interpretação dos gráficos como componentes do letramento estatístico. O diálogo aqui transcrito reitera esta afirmação.

\author{
Roseli: Essa interpretação está tão pobre! \\ Rosana: Eles não poderiam jogar mesmo, fazer o torneio de boliche? Por ser primeiro \\ ano, seria ideal, acho que deveriam fazer! \\ Keli: Poderiam! Podia virar o Torneio de Boliche da turma do Primeiro Ano da \\ Escola Tal! \\ Mie: Se fosse na sala deles seria mais legal! (Arquivo de vídeo da pesquisadora. \\ Intervalo de tempo 0:03:52 a 0:04:29).
}

As situações pedagógicas apresentadas a seguir foram destinadas ao $2^{\circ}$ ano (MILANI; IMENES; LELLIS, 2008b) e seguiam a mesma ideia da anterior (pontos do jogo de boliche), ou seja, apresentava-se uma situação em que um gráfico estava montado e depois se sugeria que as crianças montassem um novo, cujos eixos já estavam definidos e traçados, e as questões a serem respondidas, prontas. $\mathrm{O}$ assunto de uma das situações foi o brinquedo preferido de uma classe fictícia e o da outra foi o número de irmãos. No gráfico a respeito do número de irmãos, o recurso usado e reproduzido no livro didático foi a montagem das colunas com caixinhas de fósforo. Nossas discussões apontaram, mais uma vez, para um trabalho de transformação da situação pedagógica, a ser desenvolvido pelo professor:

Keli: Quando eu vejo assim no livro, acho que fica meio maçante para as crianças. Rosana: Eu estava pensando nisso. Que chato ver no livro! Eu acho muito chato! Roseli: Por quê?

Rosana: Na realidade, tudo o que tem nas fichas de trabalho, tem que dar um jeito de mudar pro concreto.

Mie: Huum.

Keli: Se eu fosse a professora do 2. ${ }^{\circ}$ ano, o que eu faria?

Rosana: Eu pediria para eles traz̧erem caixinha [de fósforo], faz̧i com eles e depois ilustrava isso aqui [falando da representação já pronta do livro didático].

Mie: E trazia fotos dos irmãos, da família, mostrava.

Rosana: Na realidade, eu faço assim: tem o material, ele é bem assim, colorido, para criança mesmo, mas eu faço sem eles olharem o material. Faço na prática. E ai depois eu só vou e registro. 


\section{Mie: Hã, hã.}

Rosana: Eles têm uma concentração para as fichas de dois minutos no máximo. O que vale é a construção. O tocar, o ver, o agir. Apenas olhar assim é até chato. (Arquivo de vídeo da pesquisadora. Intervalo de tempo 0:08:42 a 0:09:48).

A última situação pedagógica discutida indicava um trabalho com "o peso da turma toda" (MILANI; IMENES; LELLIS, 2008b, p. 178). Pedia que as crianças construíssem uma tabela em que cada criança diria seu peso ${ }^{6}$. Depois eles eram desafiados a resolver a seguinte questão: "Imagine que toda a turma suba em uma balança. Quanto marcará essa balança? Para descobrir, é preciso fazer uma conta. Nesse caso, como a conta tem muitos números convém usar uma calculadora". Depois disso, as crianças deveriam construir um gráfico em que a variável contínua "massa" havia sido separada em faixas (menos que 16, de 16 a 19, de 20 a 23, de 24 a 27, de 28 a 31 e mais de 31 quilogramas). Isso logo desencadeou no grupo uma discussão a respeito de discriminação, a qual o professor pode promover entre as crianças se houver algum obeso na turma.

Mie: Peso... Quantos quilos você pesa? Ah, não! Porque criança, às vežes...

Roseli: Já teve isso na sua escola, não teve?

Mie: É. A filha da minha amiga é meio gordinha, não vai querer falar quantos quilos pesa. Roseli: Pode constranger.

Rosana: Você tem que analisar o público que você tem, antes, para fazer uma atividade dessa?

Keli: Eu penso que na Estatística a gente classifica.

Rosana: Pesa outra coisa, então!

Keli: Pesa a mochila!

Rosana: Acho que tudo que envolve o físico é complicado.

Keli: $N a$ Estatística classificamos os dados e os resultados e nossas perguntas ressaltam, quem é o mais pesado?

Mie: Nossa! Rs. Não dá!

Rosana: Lembrei numa atividade que fiz logo no início com minha turma. Falava:

Embora essa tenha sido a palavra usada pelos autores - possivelmente, para facilitar o entendimento dos estudantes -, o correto seria "massa", ou seja, a quantidade de matéria presente em um corpo, medida pela balança em quilogramas. 
"Quem é alto?", "Quem é baixo? Começaram a brincar e en já mudei o foco e comecei a pegar os objetos da sala. Mochila, enfim, porque começou a ficar ruim.

Keli: Se você tem o cartão da criança e ela vai marcar para ela, eu sou tal, tenho tantos anos... E ela marca para ela é uma coisa, mas por uma tabela assim.

Rosana: Eu já ia surtar! Não quero que me pesem porque eu estou num momento muito difícil... rs... Terminando a faculdade... A gente come muita porcaria, dorme pouco...

Todos: Rs... (Arquivo de vídeo da pesquisadora. Intervalo de tempo $0: 27: 02$ a $0: 29: 43)$.

Outro ponto que merece destaque é que os dados para a construção desse tipo de gráfico poderiam propiciar ótimas discussões a respeito de como organizá-los e apresentá-los, mas, mais uma vez, isso não ficou a cargo das crianças.

As propostas discutidas aqui procuraram permitir a reflexão e a produção de novos significados para a prática dos professores, buscando uma sintonia com a realidade, com o contexto, com um dos materiais utilizados pelo professor, o livro didático.

\section{Algumas considerações}

Buscamos contemplar os conhecimentos elencados por Shulman (1987): o conhecimento do conteúdo da Estatística, o conhecimento pedagógico geral e da Estatística, o conhecimento dos estudantes e de suas características, o conhecimento dos contextos educativos, o conhecimento do currículo referente à Estatística e o conhecimento dos objetivos, das metas e dos valores educacionais que se entrelaçavam nos materiais que estudamos, nos encontros do grupo de estudos. Nesses estudos, também foi possível vislumbrar diferentes formas de ensinar e aprender Estatística no espaço da Educação Infantil e dos anos iniciais do Ensino Fundamental, pois procuramos não dissociar a teoria da prática. O desenvolvimento profissional do professor como desenvolvimento de si mesmo ou pessoal foi entendido como um processo pessoal, e o tempo de cada um foi respeitado. Embora alguns participantes ainda não tivessem experiência docente ou estivessem iniciando docência por meio dos estágios, buscavam, a partir de suas memórias, refletir sobre o processo de ensino e aprendizagem, contribuindo com 
depoimentos e reflexões sobre suas experiências. Consideramos, também, que isso contribuiu para que os participantes passassem a dirigir outros olhares para a prática de sala de aula e para os materiais utilizados.

As experiências que tivemos no grupo de estudos e no percurso da pesquisa reforçam o sentimento de que temos que continuar, pois nos desenvolvemos profissionalmente, num contexto colaborativo, tanto na perspectiva do letramento estatístico quanto pessoalmente. A educação e a educação estatística são áreas que carecem dessas estratégias fundamentais para a formação de professores e futuros professores.

\section{Referências}

BOGDAN, R. C.; BIKLEN, S. K. Investigações qualitativas em Educação: uma introdução à teoria e aos métodos. Porto: Editora Porto, 1994.

COCHRAN-SMITH, M.; LYTLE, S. L. Relationships of knowledge and practice: teacher learning in communities. Review of Research in Education, Washington, DC, n. 24, p. 249-305, 1999. Tradução para uso do PRAPEM (Prática Pedagógica em Matemática).

COELHO, M. A. Os saberes profissionais dos professores: a problematização das práticas pedagógicas em estatística mediadas pelas práticas colaborativas. Tese (Doutorado) - Campinas: Universidade Estadual de Campinas, Campinas, 2010.

CONTI, K. C. Desenvolvimento profissional de professores em contextos colaborativos em práticas de letramento estatístico. Tese (Doutorado) - Universidade Estadual de Campinas, Unicamp, Campinas-SP, 2015.

FIORENTINI, D. (Coord.). A investigação em educação matemática desde a perspectiva acadêmica e profissional: desafios e possibilidades de aproximação. In: Conferência Interamericana de Educação Matemática, 13., 26 a 30 de junho 2011, Recife: Universidade Federal de Pernambuco, 2011. p. 01-19. Disponível em: <http://www.cimm.ucr.ac.cr/ocs/index.php/xiii_ciaem/xiii_ciaem/paper/ viewFile/2910/1225>. Acesso em: 25 nov. 2012.

FIORENTINI, D. Desenvolvimento profissional e comunidades investigativas. In: DALBEN, A. et al. (Org.). Convergências e tensões no campo da formação e do trabalho docente: Educação ambiental - Educação em ciências - Educa- 
ção em espaços não escolares - Educação matemática. Belo Horizonte: Autêntica, 2010. p. 570-590.

FIORENTINI, D. et al. Interrelations between teacher development and curricular change: a research program. In: BEDNARZ, N., FIORENTINI, D.; HUANG, R. (Ed.). International Approaches to Professional Development for Mathematics Teachers: Explorations of innovative approaches to the professional development of math teachers from around the world. Ottawa, Ca: University of Ottawa Press, 2011. p. 213-222.

FIORENTINI, D. Pesquisar práticas colaborativas ou pesquisar colaborativamente? In: BORBA, M. C.; ARAÚJO, J. L. Pesquisa qualitativa em Educação Matemática. Belo Horizonte: Autêntica, 2004. p. 47-76.

MILANI, E.; IMENES, L. M.; LELLIS, M. Projeto Conviver. $10^{\circ}$ ano. 1. ed. São Paulo: Moderna, 2008a.

MILANI, E.; IMENES, L. M.; LELLIS, M. Projeto Conviver. $2 .^{\circ}$ ano. 1. ed. São Paulo: Moderna, 2008b.

MIZUKAMI, M. G. N. Aprendizagem da docência: algumas contribuições de L. S. Shulman. Revista do Centro de Educação da UFSM, Viçosa, v. 29, n. 2, 2004. p. 01-13. Disponível em: <http://www.ufsm.br/ce/revista/>. Acesso em: 22 set. 2014.

SHULMAN, L. S. Knowledge and teaching: foundations of the new reform. Harvard Educational Review, Cambridge, v. 57, n. 1, p. 1-22, 1987.

WATSON, J. M. Statistical literacy at school: Growth and goals. Mahwah-NJ: Lawrence Erlbaum, 2006. 